\title{
Barrett Esophagus With Metaplastic Goblet Cell Columnar Epithelium
}

National Cancer Institute

\section{Source}

National Cancer Institute. Barrett Esophagus With Metaplastic Goblet Cell Columnar

Epithelium. NCI Thesaurus. Code C157170.

A finding in an esophageal biopsy specimen indicating the diagnosis of Barrett

esophagus associated with the presence of metaplastic columnar epithelium containing goblet cells. 